\title{
SABERES DOCENTES A PARTIR DE UMA HISTÓRIA DE VIDA NA EDUCAÇÃO: COMO ME FIZ PROFESSOR
}

\author{
TEACHER KNOWLEDGE FROM A LIFE STORY IN EDUCATION: HOW I BECAME A TEACHER \\ EL CONOCIMIENTO DEL MAESTRO A PARTIR DE UNA HISTORIA DE VIDA EN EDUCACIÓN: \\ CÓMO ME CONVERTÍ EN MAESTRO
}

\author{
Edward Bertholine de \\ Castro \\ ID 9 \\ Doutor em Educação em Ciências \\ e Matemática (REAMEC/UFMT). \\ Mestre em Ensino de Ciências pela \\ Universidade Federal de Mato \\ Grosso (UFMT). \\ Professor na Universidade Federal \\ de Mato Grosso (UFMT) - \\ Campus Cuiabá.
}

\begin{abstract}
Resumo
Este texto apresenta o percurso formativo de um docente, autor e pesquisador, sujeito da própria história, contextualizado em um período de 55 anos. O objetivo foi investigar os aspectos formativos dos eventos e episódios influentes ao ensino e formação, percebidos na construção e ressignificação de saberes docentes para/sobre o ato de ensinar/formar para os anos finais do Ensino Fundamental, Ensino Médio, Educação Básica e Ensino Superior. Década a década são narrados momentos que marcaram a biografia do docente, considerando principalmente aspectos da história e política brasileira e, ainda, sua prática nas instituições em que atuou. Todo esse processo é fundamentado essencialmente na pesquisa autobiográfica. A narrativa autobiográfica permitiu um olhar holístico de um ator que vivenciou a história aqui contada, contextualizada a partir de sua percepção e concepção dos eventos, indicando a complexidade de se constituir professor que, na perspectiva freireana, é um ser inacabado, que está em constante transformação.
\end{abstract}

Palavras-chave: Autobiografia. Ensino de Ciências. Professor Formador.

Recebido em: 23 de maio de 2021.

Aprovado em: 8 de agosto de 2021.

Como citar esse artigo (ABNT):

CASTRO, Edward Bertholine de. Saberes docentes a partir de uma história de vida na educação: como me fiz professor. Revista Prática Docente, v. 6, n. 2, e050, 2021. http://doi.org/10.23926/RPD.2021.v6.n2.e050.id1302 


\section{Abstract}

This text presents the formative path of a teacher, author and researcher, subject of history itself, contextualized in a period of 55 years. The objective was to investigate the formative aspects of events and episodes influential to teaching and training perceived in the construction and resignification of teacher knowledge for/about the act of teaching/training for the final years of Elementary School, High School and Higher Education. From decade to decade, moments that marked the professor's biography are narrated, considering mainly aspects of Brazilian history and politics, and also his practice in the institutions he worked for. This entire process is essentially based on autobiographical research. The autobiographical narrative allowed a holistic look of an actor who experienced the story told here, contextualized from his perception and conception of events, indicating the complexity of constituting a teacher who, in Freire's perspective, is an unfinished being, who is constantly transformation.

Keywords: Autobiography. Science teaching. Teacher Trainer.

\section{Resumen}

Este texto presenta el itinerario formativo de un docente, autor e investigador, sujeto de la propia historia, contextualizado en un período de 55 años. El objetivo fue investigar los aspectos formativos de los eventos y episodios influyentes a la enseñanza y formación percibidos en la construcción y redefinición de saberes docentes para/sobre el acto de enseñar/formar para los años finales de la enseñanza primaria, secundaria y universitaria. Década a década son narrados momentos que marcaron la biografía del profesor, considerando principalmente aspectos de la historia y política brasileña $\mathrm{y}$, además, su práctica en las instituciones en que actuó. Todo ese proceso es fundamentado esencialmente en la investigación autobiográfica. La narrativa autobiográfica permitió una visión holística de un actor que vivió la experiencia de la historia aquí contada, contextualizada a partir de su percepción y concepción de los hechos, indicando la complejidad de constituirse profesor que, en la perspectiva de Paulo Freire, es un ser inacabado, que está em constante transformación.

Palabras clave: Autobiografía. Enseñanza de las ciencias. Profesor Formador. 


\section{INTRODUÇÃO}

Apresentaremos neste texto algumas considerações sobre os resultados de uma pesquisa de doutorado desenvolvida no Programa de Pós Graduação em Ensino em Ciências e Matemática, da Rede Amazônica de Ensino de Ciências, Polo da Universidade Federal de Mato Grosso. Trata-se de uma pesquisa que teve como foco a minha formação inicial e continuada enquanto professor formador de docentes da área de Ciências da Natureza para o ensino básico. Elegi como base investigativa episódios do meu percurso de vida escolar e profissional a partir dos anos 1960.

O interesse em discutir e desenvolver a pesquisa nesta área não surgiu por acaso. A motivação inicial neste estudo é consequente de vivências e experiências inquietantes que resultaram em constantes buscas de elementos que possam agregar significativamente na constituição de um professor formador na educação superior. $O$ meu percurso de vida acadêmica e profissional é narrado em episódios marcantes na minha memória, delimitados a partir de 1960 até 2015. Os diferentes espaços: estudante, professor e gestor universitário que percorri ao longo desse intervalo de 55 anos, e na percepção de constante incompletude, remetem meu olhar numa retrospectiva de formação docente.

A constante convicção de que sempre tenho algo a conhecer, levou-me a sentar novamente em cadeiras universitárias, no lugar acadêmico, por ocasião do ingresso no doutorado em ensino de ciências e matemática, no ano de 2015. Concordando com Freire (1996), reconheço que não sei tudo, e que posso melhorar o que sei. Nesse sentido, o meu percurso de vida profissional, analisada à luz reflexiva, move-me a compartilhar episódios para mim marcantes, com intuito de contribuir com formação de professores formadores na educação superior.

Nesta pesquisa, o objetivo foi investigar os aspectos formativos dos eventos e episódios influentes ao ensino e formação de professores percebidos na construção e ressignificação de saberes docentes para/sobre o ato de ensinar/formar em Ciências da Natureza e Biologia para os anos finais do Ensino Fundamental e Ensino Médio da Educação Básica, no sujeito formador docente da educação superior, no período de 1960 a 2015, com maior ênfase nos anos significativos no meu percurso do vir a ser professor formador.

\section{NARrativa Autobiográfica}

O sentido da totalidade é resultado de uma construção advinda da diversidade de fontes de informações, tratadas como documentos, enfocando particularidades e características da 
vida. Segundo Novoa (2007, p. 68), “A reflexão sobre a própria vida revela ao sujeito suas relações com as experiências formadoras que constituem a marca da historicidade".

A pesquisa narrativa autobiográfica reconhece a voz do sujeito, valoriza suas falas, percebendo-o como protagonista de sua história. Daí porque faz-se importante recuperar e revisar eventos e episódios como itinerários da minha vida profissional, articulando e interagindo com o passado e o presente, quiçá o futuro.

Tendo como referência a realidade (nesse estudo a realidade sob a minha percepção), Freire diz que se faz necessário pensar e agir conscientemente sobre ela para almejar sua transformação social. E essa consciência crítica passa por uma educação que possibilite a vivência de uma análise crítica da realidade em contexto.

[...] exige uma presença curiosa do sujeito em face do mundo. Requer sua ação transformadora sobre a realidade. Demanda uma busca constante, implica em invenção e em reinvenção. Reclama a reflexão crítica de cada um sobre o ato mesmo de conhecer, pelo qual se reconhece conhecendo e, ao reconhecer-se assim, percebe o "como" de seu conhecer e os condicionamento a que está submetido seu ato (FREIRE, 2005, p. 27).

Como se vê, a curiosidade indagadora, metódica, numa ação epistemológica de reflexão e ação, leva a leitura de mundo e produção de conhecimento. O olhar retrospectivo para os eventos e episódios que foram relevantes, sob minha perspectiva, para a formação profissional enquanto professor formador, remete à consciência de que a pessoa humana está sempre em construção. A leitura de mundo em seus contraditórios me move a constantes buscas. A forma como Freire entende o movimento crítico-dialético considera que:

\footnotetext{
O melhor ponto de partida para estas reflexões é a inconclusão do ser humano de que se tornou consciente. Como vimos, aí radica a nossa educabilidade bem como a nossa inserção num permanente movimento de busca em que, curiosos e indagadores, não apenas nos damos conta das coisas, mas também delas podemos ter um conhecimento cabal. A capacidade de aprender, não apenas para nos adaptar, mas, sobretudo para transformar a realidade, para nela intervir, recriando-a, fala de nossa educabilidade a um nível distinto do adestramento dos outros animais ou cultivo das plantas (FREIRE, 2005, p. 76).
}

Como o aprender, na visão freireana, compreende um movimento de buscas, tem nele a essência problematizadora, que gera e resulta em mudanças qualitativas. A curiosidade inquietante movida pela exigência metódica contempla um exercício dialético da realidade concreta, como expressa Freire:

Admirar, um olhar por dentro, separar para voltar a olhar o todo admirado, que é um ir para o todo, um voltar para suas partes, o que significa separá-las, são separações que só se dividem pela necessidade que o espírito tem de abstrair para alcançar o concreto. "No fundo são operações que se implicam dialeticamente" (FREIRE, 1996, p. 44). 
A dialética freireana considera as relações estabelecidas entre objetos e fatos da realidade, embasadas pela conscientização. A curiosidade desafiadora, metódica, crítica, para compreender as relações das partes e de cada uma com o todo, considera o contexto históricosocial da realidade. Essas relações, submetidas a análises possibilitam a construção de um conhecimento mais amplo, indo além das abordagens de dimensões parciais.

Por isso, a dialética-dialógica permeia os relatos que constituem a narrativa, uma vez que essa reflexão freireana fez parte - inicialmente talvez até inconsciente, mas depois de uma forma consciente- do meu vir a ser professor formador de professores de Ciências da Natureza para os anos finais do Ensino Fundamental e de Biologia para o Ensino Médio.

\section{Metodologia}

\subsection{METODOLOGIA DA PESQUISA}

Como metodologia de pesquisa elegemos a abordagem qualitativa. O uso desse tipo de pesquisa, na educação, advém dos campos da Antropologia, Psicologia e Sociologia, que trabalhavam com seus dados sob um olhar descritivo. Passa a ser aceita pela proximidade na forma de lidar com as informações, como por exemplo, escritos orais, história de vida, estudos de casos, dentre outros. Segundo Bogdan e Biklen (1994, p. 47), na abordagem qualitativa podem constar cinco características:
a) a fonte primária dos dados é o ambiente natural, onde o investigador é o instrumento principal;
b) descritiva;
c) o processo é mais importante que os resultados;
d) os dados são analisados de forma indutiva;
e) o significado assume fundamental importância.

$\mathrm{Na}$ educação, a pesquisa de abordagem qualitativa traz constantemente $\mathrm{o}$ questionamento e o diálogo com os pesquisados, no propósito de identificar como percebem suas experiências. Essa concepção é reforçada pelos discursos teóricos de Psathas (1973 apud BOGDAN; BIKLEN, 1994) e Triviños (1990). A pesquisa qualitativa não está sujeita à rigidez no desenvolvimento de etapas na coleta e análise de dados, onde essas não precisam ser eventos estanques. Os dados coletados podem ser interpretados e, a partir disso, evidenciarem a necessidade de buscar mais informações.

Nessa modalidade de pesquisa, a interpretação considera a subjetividade porque é realizada pelo investigador sobre algo, solicitando que se faça a descrição e compreensão de 
dados que uma abordagem quantitativa não consegue responder. Ainda assim, mantem-se o rigor científico como caracteriza uma pesquisa acadêmica. Desta forma, para este estudo investigativo usou-se o método autobiográfico, tendo como ferramentas as narrativas de memórias (VIDAL, 1998). Conforme Aragão (1993, p. 5),

[...] narrar constitui uma estrutura fundamental da experiência humana vivida e da comunicação dos seres humanos uns com os outros. Talvez, por isso, apresente uma qualidade holística, uma vez que possibilita a todos nós a expressão da história do nosso ponto de vista, do lugar de onde podemos olhar e ver... não só com os olhos, mas principalmente com a mente.

Nesta perspectiva, as investigações pelo viés da narrativa se propagaram nos anos de 1980 em que a autobiografia faz parte de tal modalidade investigativa. No Brasil, essa tendência tem sido contemplada em pesquisas nas últimas décadas. Baseando-se no autor Chaves (2010, p. 19),

Nessa visão podem ser mencionados, como trabalhos que estão relacionados com a narrativa, as investigações de Schulman sobre professores especialistas (1987), os de Munby sobre as metáforas dos professores (1986) e o de Willis (1990) sobre processos de aprendizagem da cultura conta-escolar de trabalhadores, dentre outros.

$\mathrm{Na}$ narrativa autobiográfica os dados podem ser produzidos a partir de diferentes documentos. Sendo assim, neste estudo contemplo como instrumentos a ficha funcional, portarias institucionais, leis, imagens, informes de contextos políticos, sociais e científicos em nível mundial e nacional, princípios pessoais e a minha memória.

Os relatos de eventos e episódios foram analisados a partir de unidades de análise definidas a priori. Cada unidade de análise contém os grupos, conforme Quadro 1.

Quadro 1 - Unidades de Análise e grupos constitutivos

\begin{tabular}{|c|c|}
\hline UNIDADES DE ANÁLISE & GRUPOS \\
\hline \multicolumn{2}{|c|}{ UNIDADE DE ANÁLISE 1} \\
\hline \multirow{3}{*}{$\begin{array}{c}\text { Processos de educação vivenciados e } \\
\text { experienciados }\end{array}$} & 1a) vida escolar/acadêmica \\
\hline & $\begin{array}{l}\text { 1b) regime de governo: militar, abertura política, } \\
\text { inclusão social, pós-golpe }\end{array}$ \\
\hline & 1c) concepção de Ciência \\
\hline \multicolumn{2}{|c|}{ UNIDADE DE ANÁLISE 2} \\
\hline \multirow{4}{*}{$\begin{array}{l}\text { Percurso da vida profissional } \\
\text { [formação e condição docente] }\end{array}$} & 2a) Ingresso na docência \\
\hline & $\begin{array}{l}\text { 1b) regime de governo: militar, abertura política, } \\
\text { inclusão social, pós-golpe }\end{array}$ \\
\hline & $\begin{array}{l}\text { 2c) Motivos que me motivaram no exercício da docência } \\
\text { e para o "vir a ser" }\end{array}$ \\
\hline & 2d) concepção de Ciência \\
\hline
\end{tabular}

Fonte: Castro (2019). 
Essas unidades de análise foram trianguladas com a concepção das necessidades formativas para os professores, segundo minhas convicções e de teóricos da área de educação e de formação de professores em Ciências Naturais e Biologia.

E, por fim, o resultado dessa triangulação foi discutida, embasada em teóricos como Krasilchik (1987) e Morin (2003), considerando contextos macro, meso e micro nos aspectos político-econômicos, educacionais e institucional, de forma a evidenciar quais foram os aspectos formativos que participaram na construção e ressignificação de saberes enquanto professor formador de professores em Ciências da Natureza e Biologia, para os anos finais do Ensino Fundamental e Ensino Médio.

\subsection{Procedimentos metodológicos}

\subsubsection{O SUJEITO da PESQuisa}

Por se tratar de uma investigação autobiográfica, o sujeito da pesquisa coincide com o próprio pesquisador. Na condição de sujeito, faço uso da historicidade de vivências e experiências significativas, compreendidas como aprendizagens no percurso da vida acadêmica e profissional.

\subsubsection{InStrumentos de Produção de Dados-IPD}

Para o desenvolvimento desta pesquisa foram observados os seguintes procedimentos metodológicos: levantamento bibliográfico e documental, identificação de eventos e episódios relevantes na minha formação profissional, descrição e análise desses contextos.

\subsubsection{LEVANTAMENTO E ESTUDO BIBLIOGRÁFICO E DOCUMENTAL}

Utilizou-se como fundamentação teórica a pesquisa bibliográfica, um tipo de pesquisa que permitiu aprofundar a análise teórica do tema em pauta e ajudou a investigar e compreender os objetos de estudo com maior objetividade. Sendo assim, busquei diálogos com Fabre (1994), Novoa (2007), Freire (1996), Garcia (2006), Gatti, Barreto e André (2011) que analisam a formação continuada do professor.

Entende-se por documento as várias formas de registro, além de diferentes imagens, compondo o que se chama de fonte primária de informação. Segundo Marconi e Lakatos (2006), esses documentos podem ser escritos ou não, sendo coletados no momento presente ou após o fato ocorrido. 
Lüdke e André (1986) considera que essa técnica possibilita que se retirem evidências que possam fundamentar afirmações do pesquisador. A análise dos discursos identificados a partir dos documentos possibilita o acesso a uma realidade sob outra perspectiva, contribuindo para a validação mediante a triangulação de estratégias de coleta de dados.

Ainda, além de expressar a realidade de um contexto e fatos, é preciso atentar que são construções humanas, com uma finalidade prática, visando certo uso e acesso. E é nisso que reside a análise documental.

Conforme Gil (2010, p. 68), a pesquisa documental se resume "em: escolha e organização das fontes de informações; estudo detalhado com descrição analítica; tratamento e interpretação".

As etapas a serem observadas na análise documental são apresentadas na figura 1, a seguir.

Figura 1 - Esquema dos procedimentos para a análise documental

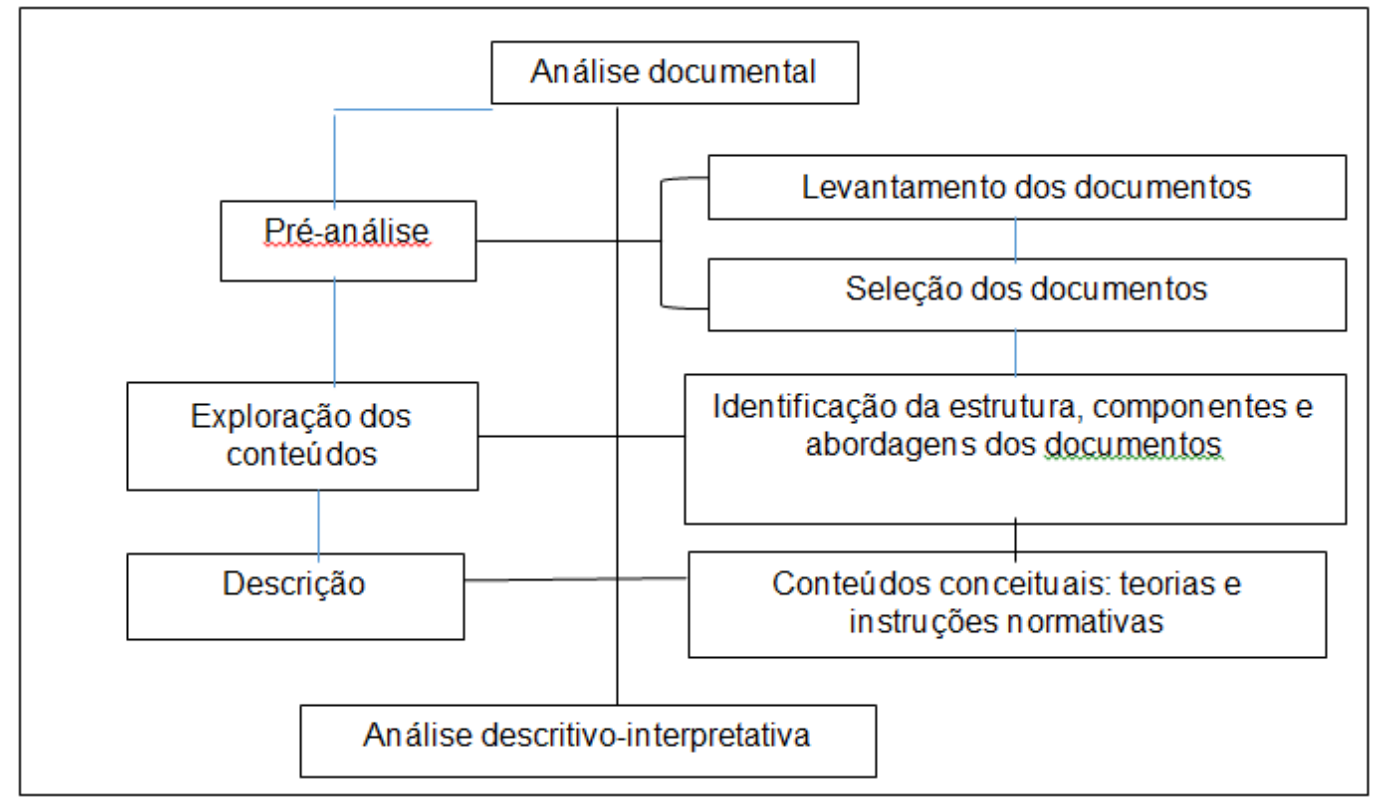

Fonte: Castro (2019).

\section{RESUltados E DiscuSSÃO}

Apresento inicialmente uma linha histórica dos eventos de relevância (figura 2), por meio dos quais será estruturada a discussão que faço aqui. Em cada década é possível visualizar o contexto de abordagem escolhido para as narrativas acerca do percurso do narrador. 
Figura 2 - - Linha Histórica dos Eventos de Relevância na Formação do Autor

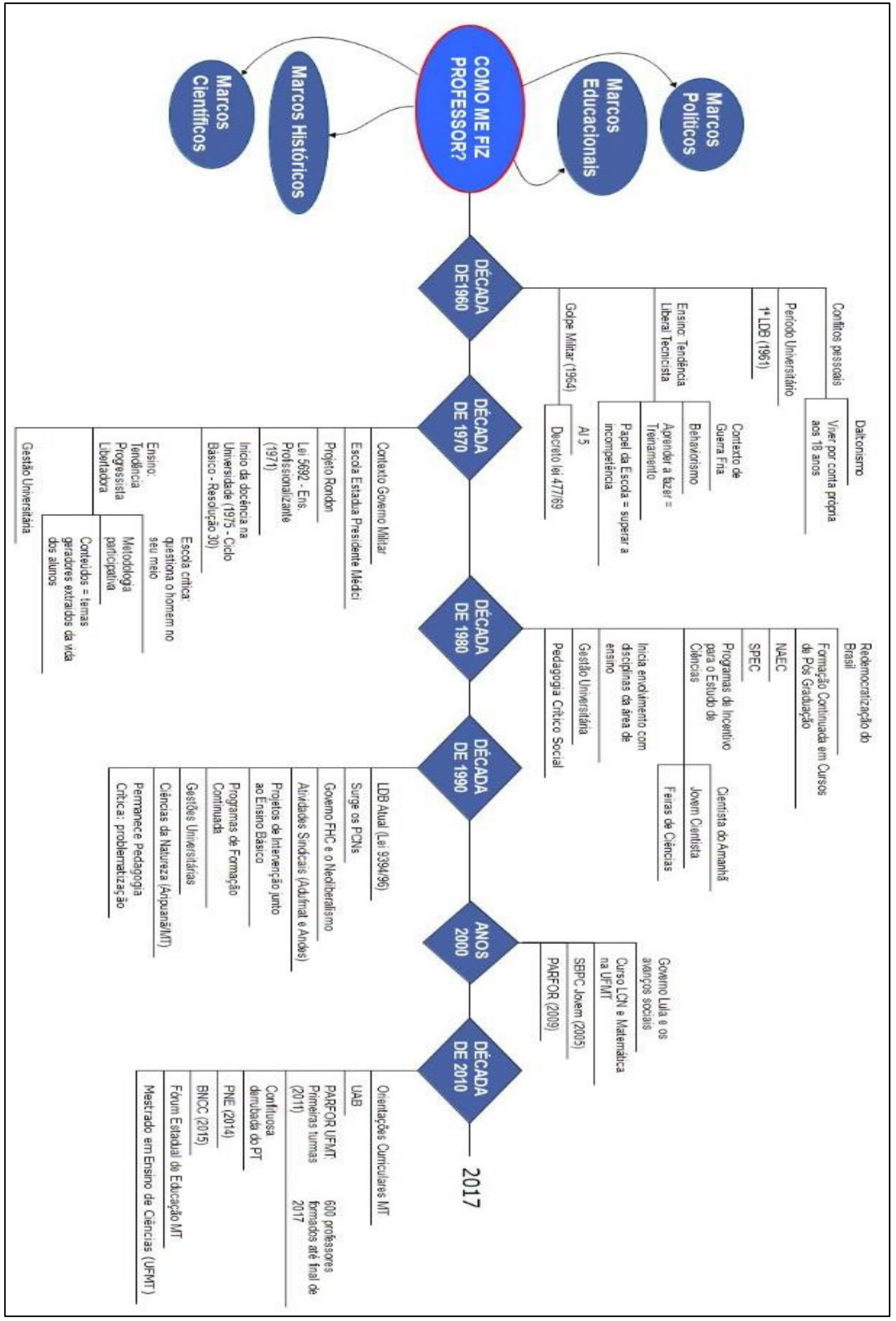

Fonte: Castro (2019). 


\subsection{Marcos Históricos, Políticos, Científicos e Educacionais - Anos de 1960 E} 1970

Os eventos e episódios contemplados a seguir na década de 1960 tratam de um breve panorama da minha formação escolar e acadêmica. Para tanto, considero alguns conflitos pessoais como o fato de ser daltônico e a entrada na vida universitária como acadêmico ${ }^{1}$. Já os eventos e episódios analisados na década de 70 são percebidos no contexto de complexas interações no início da minha docência, considerando situações vividas, percebidas e experienciadas em seus contraditórios. Trata-se de uma época de regime militar.

Entre os anos finais de 1950 e o início dos anos 1970 cursei o ensino Primário² (por onde passei por escolas confessionais e públicas - de regime seriada e multisseriada) o Ginasial, Colegial e Ensino Superior em História Natural nas modalidades de Licenciatura Plena e Bacharelado.

No decorrer da minha escolarização predominava o ensino tradicional que se caracterizava em não permitir questionamentos, em função dos processos didáticos- dedutivos. O ensino e aprendizagem baseavam-se no princípio de que a partir dos conhecimentos abstratos poder-se-ia chegar à compreensão do concreto, ou ainda, do geral para o específico. A principal ferramenta pedagógica eram os livros textos repletos de conteúdos conceituais. Nessa prática pedagógica o professor era o centro do processo de ensino e aprendizagem. Não havia consideração ao que o aluno sabia ou mesmo ao seu contexto de vida.

Neste ambiente de aprendizagem o estudante era visto como uma "tábula rasa", visto por Freire (2005) como sendo uma educação bancária, em analogia a uma folha de papel em branco, sem nenhum conteúdo, onde todos tinham as mesmas características psicológicas, somáticas e comportamentais. Essa visão de educação acarretou em grande trauma na minha construção enquanto sujeito capaz de aprender e de superar dificuldades e obstáculos. Durante meu processo educacional, por ser daltônico ${ }^{3}$, era considerado uma criança com dificuldade de aprendizagem.

\footnotetext{
${ }^{1}$ Cursei a graduação no período de 1969 a 1972 nos cursos de bacharelado e de licenciatura plena em História Natural.

${ }^{2} \mathrm{O}$ ensino Primário corresponde ao que hoje temos como anos iniciais do EF, ou seja, do $2^{\circ}$ ao $5^{\circ}$ ano; Ginasial, corresponde ao que hoje temos como anos finais do EF, ou seja, da $6^{\mathrm{a}}$ a $9^{\mathrm{a}}$ séries/EF. Colegial corresponde ao que temos hoje com Ensino Médio.

${ }^{3}$ Somente 09 anos de idade, e estava na quarta série primária. No decorrer dos anos de escolarização anteriores a isso, fui tratado como alguém com dificuldade de aprendizagem especialmente por não conseguir realizar adequadamente as tarefas que exigiam o uso de cores, como por exemplo, colorir estados segundo cores prédefinidas na atividade. Por esses "erros", era considerado "preguiçoso".
} 
Com esse "diagnóstico" nas tarefas que envolviam o uso de cores - estratégia muito utilizada à época nos processos de avaliação que solicitavam identificações de seres vivos, reconhecimentos de relevos entre outros conteúdos - os resultados que eu obtinha não eram satisfatórios, acarretando constrangimentos e castigos, tanto na escola quanto na família.

Este fato gerou em mim sentimentos que considero como perversos e que influenciaram, sobremaneira, na minha percepção enquanto sujeito provido de possibilidades para aprender, de me ver e me sentir no mundo.

Percebia minha existência fadada ao fracasso, sendo incapaz e, consequentemente, incompetente para viver no ambiente de aprendizagem ${ }^{4}$. Esta situação foi um pouco atenuada pela atitude da professora Tábata, que me presenteou com caixa de lápis em cores com um índice numerado, me possibilitando identificar as cores. Esta professora apareceu na minha vida quando eu estudava na Escola Estadual Raul Vidal, em Niterói-RJ.

Segundo a visão platonista, para enveredar-se no processo do aprender, é preciso dominar os ídolos da caverna, da tribo, do foro e do teatro. Essa minha experiência escolar contribuiu para a construção de algumas "cavernas" de incompetência, mas também de um primeiro referencial de educador. Segundo Oliveira (2000, p. 33):

Os ídolos da caverna (ídola specus) são próprios do indivíduo e se acham enraizados nas profundezas da alma de cada um de nós. São formados pela educação recebida, pela convivência familiar e com outras pessoas ou, até mesmo, a partir da leitura de livros e da admiração dispensada a certas pessoas.

Trata-se também de um período em que a primeira Lei de Diretrizes e Bases da Educação Nacional, a LDB 4024/61, que vigorou num contexto de golpe militar (1964), sob a força do AI 5 e Decreto Lei 477/69.

Após a promulgação da LDB/61, a Educação Brasileira passou por intensas experimentações e transformações pedagógicas. Com a intensificação do processo de mobilização popular, foram surgindo movimentos com foco na educação, entre os quais o Movimento de Educação de Base (MEB) e o Movimento Paulo Freire de Educação de Adultos.

Quando houve o Golpe Militar, em 31 de março de 1964, cursava o quarto ano do Ginasial (atual ensino fundamental II). Impossível não perceber um ambiente diferente em nosso cotidiano. Entretanto, não tinha noção do que ocorria, apenas observava que havia algo de estranho a partir dos movimentos e comentários sobre a situação, já que as aulas haviam sido suspensas sem maiores esclarecimentos.

\footnotetext{
${ }^{4}$ Entenda-se "ambiente de aprendizagem” espaços escolares e não escolares. 
Já no Colegial (hoje, Ensino Médio), na época denominado de Científico, participando dos movimentos sociais e, mais tarde, dos movimentos estudantis, passei a tomar conhecimento das reformas realizadas na Educação Brasileira, evidenciadas a partir da exclusão do exame de Admissão. Para essa seleção, antes obrigatória ao prosseguimento dos estudos, escolas particulares ofereciam cursos preparatórios, nos quais os alunos dos últimos anos do Ginasial eram convidados a ministrarem aulas para os candidatos ao Exame de Admissão.

Os anos 1970 marcaram um período de muitas mudanças movidas por intensas mobilizações e lutas. Em 1970 e 1971 participei do Projeto Rondon como acadêmico, e em 1972 e 1973 como supervisor de operações junto a Fundação Movimento Universitário de Desenvolvimento Econômico e Social - Fundação MUDES. Em 1975 ingressei como professor na Escola Estadual Presidente Médici, em Cuiabá-MT.

No segundo semestre desse mesmo ano deu-se o início da minha docência na Universidade Federal de Mato Grosso- UFMT, como docente em sala de aula e, após alguns meses, também como coordenador de atividades educacionais junto aos professores de Ciências do $1^{\circ}$ Grau e $2^{\circ}$ Grau (hoje denominados anos finais do Ensino Fundamental e Ensino Médio) no contexto das licenciaturas curtas.

No período de 1975-1976 atuei como membro do colegiado de curso junto ao departamento de licenciatura em Ciências. De 1976 a 1977 fui coordenador de área. De 1976 a 1977 fui coordenador de área de Ciências Biológicas e da Saúde do ciclo básico ${ }^{5}$. Após aprovação em exame de seleção para auxiliar de ensino, em 1979 assumi, na UFMT, como professor assistente ${ }^{6}$ para o Centro de Ciências Biológicas e da Saúde.

\subsection{Marcos Históricos, Políticos, Científicos e Educacionais - Anos de 1980}

Em relação aos anos 80, estabeleço interlocuções da minha vivência e experiência na docência e gestão universitária. As ações científicas e políticas por mim aqui contempladas nos contextos e espaços da docência universitária são: minha formação continuada como estudante de pós-graduação/especialização; implantação e coordenação do Núcleo de Apoio ao Ensino de Ciências-NAEC/UFMT no período de 1981 a 1983; avaliador junto a eventos como Cientista

\footnotetext{
${ }^{5}$ Fazendo uma analogia, esse ciclo básico da época correspondia ao que denominamos núcleo comum na matriz curricular em um curso.

${ }^{6}$ Primeira classe e primeiro nível na carreira docente universitária. 
do Amanhã, Jovem Cientista (SBPC) e Feiras de Ciências (nível municipal, estadual); docente em disciplinas da área de ensino ${ }^{7}$.

Em atividades de gestão universitária, delimito para análise os episódios: gerente de atividades comunitárias da Coordenação de Assuntos Comunitários (1980); membro da Comissão de Assuntos de Interior $^{8}$ (1981-1983); coordenador de extensão/CODEX-UFMT (1981 a 1983).

Os anos de 1980, sob regime militar, traz marcas de movimentos para a redemocratização do Brasil. A aprovação da Constituição Brasileira em 1988 (BRASIL, 2016), tida como constituição cidadã pode ser compreendida como consequência, pelo menos em parte, desses movimentos sociais de lutas pela queda do regime militar no país.

Convergente a esse posicionamento de questionamento do status socioeconômico e político brasileiro, a pedagogia crítico social, na visão freireana, passa a integrar pensamentos, ações e decisões no âmbito universitário.

A formação de professores de ciências naturais começou a ser debatida nos principais congressos sobre educação, especialmente após o final dos anos 1970 e começo de 1980, período em que permaneceu em discussão a obrigatoriedade de reformulação nos cursos de superiores da área de ciências naturais (ARROYO, 1988).

Na década de 1980 o viés pedagógico alcançou um expressivo nível de qualidade e pluralidade, sobretudo através do aparecimento da teoria crítica, das teorias sociointeracionistas, da pedagogia democrática, entre outras. As teorias educativas que avaliavam a escola como mera reprodutora das relações sociais povoaram as discussões no que tange à formação de professores e lograram grande influência sobre certas disciplinas da área das ciências naturais.

Desse modo, a formação de professores e o processo pedagógico passaram a ser vistos como uma atividade repleta de pluralidade e complexidade. Nesse sentido, o chão da escola passou a ser considerado consoante um ambiente de contradições, em que novos ideais e transformações poderiam ser postas em prática (MATHEWS, 1995).

O Comitê Nacional Pró Formação do Educador principiou, nos anos 80, um movimento em prol da readequação dos cursos formativos de professores, sugerindo a terminalidade dos

\footnotetext{
${ }^{7}$ De 1975 a 1986 trabalhei como docente universitário em disciplinas de referência. Em 1986 assumo a cadeira de Estágio Supervisionado, dando entrada como professor na área de ensino, permanecendo até os dias atuais.

${ }^{8}$ Planejava e desenvolvia atividades de formação continuada para professores da Educação Básica de municípios do interior de MT.
} 
cursos de licenciatura com curta duração. O MEC, em 1983, instituiu a CONARCFE Comissão Nacional de Reformulação dos Cursos de Formação do Educador - ficando clara a existência de um lapso entre as intenções do governo em relação aos posicionamentos defendidos pelos peritos e pesquisadores da área educacional (BENITE, 2009).

A partir do começo de 1980 os debates a respeito da formação dos professores indicavam que o docente precisaria tomar consciência sobre a função da escola na mudança das práticas sociais dos educandos e das nuances das bases educacionais, tornando-se, assim, mais ampla e democrática (ARROYO, 1988).

O conceito do novo professor de ciências dos anos 80 floresceu em aversão à antiga realidade do especialista técnico que apenas facilitava a aprendizagem, da figura caracterizada como mero organizador de conteúdos, ou seja, daquele professor técnico comum aos anos 1970. Nos anos de 1980, porém, o dialogismo entre professor educador começou a ser visto como algo menos importante na conjuntura educacional do Brasil (ARROYO, 1988).

No mundo, sob a égide da revolução tecnológica, inicia-se a era das comunicações a partir de tecnologias como o celular, os CDs, computador e a internet.

\subsection{Marcos Históricos, Políticos, Científicos e Educacionais - Anos de 1990}

Os anos de 1990 iniciam com o colapso da União Soviética e com o fim da Guerra Fria, fatos que muito contribuíram para grandes mudanças, como também para com o processo de globalização, sob a égide da prosperidade econômica.

No Brasil esses anos iniciam com o confisco da Poupança pelo governo Collor que, juntamente com outros escândalos ligados à corrupção, mobilizou os jovens em torno do movimento "caras-pintadas" culminando com o "Impeachment" e, consequentemente, com a posse de Itamar Franco.

Experimentamos, no início dos anos Itamar, uma estabilidade econômica com o crescimento do Plano Real lançado em 1994, pelo então Ministro da Fazenda Fernando Henrique Cardoso, que mais tarde tornar-se-ia Presidente da República por dois mandatos, compreendendo o período de 1994 a 2002.

O Plano Real continha, entre outras, medidas como corte de gastos públicos, paridade no valor do dólar e real, recuperação da receita, atração de capital especulativo internacional e privatizações. Com essas características gerou-se um ambiente de insatisfação junto aos grupos socialmente organizados, em função do aumento da pobreza nos grandes centros urbanos e, 
com a ameaça de privatização das universidades públicas, uma mobilização da comunidade acadêmica nunca visto antes.

A década de 1990, para mim, se configura como a década dos desafios com a percepção e atuação crítica-reflexiva frente ao fazer-se professor. Além da docência, a participação na gestão universitária passa pela compreensão das potencialidades e limitações em instâncias decisórias.

Em nível macro político, se caracterizam o neoliberalismo e a globalização. No Brasil, com o presidente eleito Fernando Henrique Cardoso, temos a abertura para a implantação de políticas neoliberais na gestão pública. Como reflexos desses interesses, a educação de qualidade passou a ser avaliada a partir de habilidades e competências definidas nos Parâmetros Curriculares Nacionais (PCNs).

No contexto de abertura política, com a Constituição Federal de 1988, a educação ainda estava sob as normas da Lei 5692/71, da época do regime militar. A nova LDB foi promulgada em 1996, sob n 9394/96 (BRASIL, 1996) e, mesmo com várias alterações, continua em vigor até os dias de hoje. A tendência pedagógica crítica social se faz presente como chamada a problematização de realidades numa visão dialética.

A visão de Ciência predominante era da Ciência aplicada, uma vez que se intensificava áreas de pesquisa que produzissem tecnologias para atender as demandas das competitividades no mercado internacional.

Nesse cenário, participei do ANDES - Sindicato Nacional como vice-presidente regional pantanal. De 1994 a 1996, assumi a função de Chefe de Departamento de Biologia e Zoologia. Desenvolvi, nessa época, vários projetos de intervenção junto à educação básica, como atividades extensionistas, onde destaco "UFMTrilha" e "Venha conhecer sua universidade".

Participei também da construção do curso "Ciências da Natureza e Matemática Interdisciplinar", de formação de professores para a educação básica, a nível de graduação. Esse curso inicialmente previsto para ser desenvolvido em Aripuanã, só foi efetivado em 2001, em Cuiabá, onde atuei como professor.

Para além das questões educacionais, nessa década ocorreram eventos que, de certa forma, tiveram influências no processo de formação e no desenvolvimento de profissionais da educação para a área de Ciências da Natureza como a Conferência das Nações Unidas sobre o Meio Ambiente e o Desenvolvimento - Eco-92, assim como o Tratado de Kyoto. A Eco-92, 
organizada pelas Nações Unidas, ocorreu no Rio de Janeiro no período de 3 a 14 de junho de 1992.

No evento se reuniram chefes de Estados com o objetivo de debater os problemas ambientais mundiais. Como resultado foram produzidos documentos oficiais de fundamental importância para o processo de sensibilização das questões ambientais e o do futuro do Planeta, como a Carta da Terra, Convenção sobre Diversidade Biológica, Convenção das Nações Unidas de Combate à Desertificação, convenção sobre Mudanças Climáticas Globais, Declaração de Princípios sobre Florestas, Declaração do Rio sobre Meio Ambiente e Desenvolvimento e a Agenda 21.

A partir desses debates intensificaram-se as pesquisas sobre o ensino de Ciências, como também a forma de trabalhar os conhecimentos científicos com as gerações futuras, na perspectiva da construção e da manutenção de uma sociedade sustentável, na qual a Educação Ambiental passa a ser uma das possibilidades de estudos e encaminhamentos metodológicos.

O grande desafio era o de como superar, nos processos formativos e educacionais, a visão de que o adendo Ambiental, para identificar uma educação necessária para a formação cidadã, não se tratava de um adjetivo e sim um qualificativo.

Foi um momento de grande desestruturação, enquanto profissional formador, assim como de busca de novos referenciais teóricos/filosóficos e de novos grupos, nos quais poderia ancorar minhas dúvidas, angústias e a vontade/necessidade de superação, já que, cada vez mais, percebia o significado do "compromisso social" freireano.

\subsection{Marcos Históricos, Políticos, Científicos E Educacionais - Anos 2000}

A virada do século XX para o XXI é marcada pela incerteza do calendário. Os sistemas computacionais corriam o risco de desaparecer com todos os dados cadastrados, uma vez que a descrição do ano era dada (e ainda é) pelos dois últimos algarismos e, sendo assim, o primeiro de janeiro do ano 2000 poderia ser entendido pelos computadores como ano 1900, o que geraria transtornos de proporções universais em contas bancárias, sistemas aéreos, enfim, um caos total. Não ocorreu nada, a vida seguiu após a desestruturação gerada pelo desconhecido, por algo relativamente simples, mas que provocou extensas discussões na sociedade.

Este evento, parafraseado das palestras do mestre Áttico Chassot (CHASSOT, 2016), serve para contextualizar como a transição de um século para outro foi incerta em diversos aspectos. A imprevisibilidade dos fenômenos ganha força nas discussões filosóficas/ científicas 
e passa a confrontar o positivismo, em um ensaio de uma possível transição de paradigma (RAMOS; NEVES; CORAZZA, 2011).

Na política nacional, os primeiros anos do novo século foram marcados pela saída de um governo neoliberal e a entrada de Luís Inácio Lula da Silva, um ex-metalúrgico, sindicalista, considerado preocupado com as questões sociais. A estabilidade econômica alcançada no governo Fernando Henrique era agora colocada à prova num governo social democrata taxado ora como de esquerda, ora de comunista.

Em sua gestão ocorreram significativos avanços sociais, como: real aumento do salário mínimo e poder de compra da população de menor renda financeira; expansão universitária; aumento no acesso ao Ensino Superior, com a implantação de políticas inclusivas para garantir a permanência de acadêmicos de baixa renda.

Programas como o Brasil Alfabetizado e Educação para Jovens e Adultos, o Universidade para Todos, a universalização dos livros didáticos para a escola básica, são exemplos de mudanças significativas na política educacional.

Na UFMT, no período de 2001 a 2004 atuei como professor no curso de Ciências da Natureza e Matemática Interdisciplinar. Este se caracterizou com uma abordagem curricular e de ensino interdisciplinar. Em 2005, coordenei o evento SBPC Jovem na UFMT-Cuiabá. No período de 2009 a 2015 fui coordenador institucional do Programa de Formação de Professores - PARFOR (LELLIS; MUELLER, 2017), vinculado a CAPES.

\subsection{Marcos Históricos, Políticos, Científicos E Educacionais - de 2010 A 2015}

No último período desta análise, anos 2010 a 2015, passei por um olhar inclusivo frente às demandas sociais e a consciências por uma prática social política problematizadora. Percebi como "período do amadurecimento", uma vez que assumi as competências políticas e científicas na ação docente, configurando-se como interlocução de continuum dialéticodialógico.

Como parte de minha formação acadêmica, entre 2010 e 2012, cursei o mestrado no programa de Pós-graduação em Ensino de Ciências/UFMT e fui consultor na produção na área de Ciências Naturais e Biologia para a Educação Básica, para as Orientações Curriculares no estado de Mato Grosso. Continuei como coordenador do PARFOR (2009-2015).

No ano de 2014 foi aprovado o Plano Nacional de Educação - PNE. Em 2015 iniciei minha formação em nível de doutorado junto ao Programa REAMEC. 


\section{CONSIDERaÇões Finais}

Todos os relatos pontuam uma trajetória riquíssima em constructos e conflitos, intrinsecamente dependentes, num movimento constante de reflexão acerca do ser/tornar-se professor.

Considero o vir a ser professor formador, neste contexto, um produto sempre incompleto da vivência que produziu saberes em mim, e do quanto eu soube transformar esses saberes em instrumentação de formação pessoal e profissional.

Ter transitado por tantos acontecimentos foi um privilégio do qual não posso me furtar de reconhecer, pois acredito ser a experiência vivida, não só aquela observada, a maior responsável pela desconstrução e reconstrução de formas de interpretar, formas de pensar e de agir! Deriva dela muitas das nossas habilidades em lidar com situações e fenômenos, numa constante busca por criticidade. Ter sido professor ao mesmo tempo que vivi todas essas experiências contribuiu significativamente para que essa 'bagagem' não deixassem de dar sentido à minha formação.

Em trabalhos futuros buscarei, cada vez mais, dar sentido contextual às formações sob minha responsabilidade. O lugar do contexto não pode mais ser ignorado pelas reformas educacionais, como se a educação tivesse condições de ser protagonizada da mesma maneira para todas as pessoas. Num país absolutamente multicultural e de dimensões continentais como o Brasil, contextualizar a educação é um ato de coragem dos educadores. No meu caso um pouco mais, um ato de reconhecimento do quanto os contextos, ao longo da minha história, me fizeram o formador que me tornei.

\section{REFERÊNCIAS}

ARAGÃO, Rosália Maria Ribeiro. de. Reflexões sobre Ensino, Aprendizagem, Conhecimento... In: Revista de Ciência \& Tecnologia. Piracicaba-SP: Editora UNIMEP, Ano 2, $\mathrm{N}^{\circ}$ 3, Julho/1993.

ARROYO, Miguel. A função social do ensino de ciências. Em aberto, v. 7, n. 40, p. 3-11, 1988.

BENITE, Claudio Roberto Machado. Discussão curricular a partir do tema energia numa perspectiva de intervenção na formação continuada de professores. 2009. 113f.

Dissertação de Mestrado. Universidade Federal de Goiás, Goiânia, 2009.

BOGDAN, Robert; BIKLEN, Sari. Investigação qualitativa em educação. Porto: Porto Editora, 1994. 
BRASIL. Constituição da República Federativa do Brasil. Brasília: Senado Federal, Coordenação de Edições Técnicas, 2016. 496 p.

BRASIL. Lei de Diretrizes e Bases da Educação Nacional. Brasília: MEC, 1996.

CASTRO, Edward Bertholine. Trajetória, processo formativo e saberes docentes: estudo Autobiográfico sobre memórias e ressignificações de um Formador de professores para educação básica na área de ciências biológicas. Tese Doutorado. Programa de Pós Graduação em Educação em Ciências e Matemática (PPGECEM) da Rede Amazônica de Educação em Ciências e Matemática (REAMEC). Universidade Federal de Mato Grosso, Cuiabá, 2019.

CHASSOT, Áttico Inácio. Das disciplinas à indisciplina. Curitiba: Appris, 2016.

CHAVES, Silvia Nogueira. A construção coletiva de uma prática de formação de professores de ciências: tensões entre o pensar e o agir. Campinas: FE/UNICAMP, 2000. (Tese de Doutorado).

FABRE, Michel. Penser la formation. Paris: Presses Universitaires de France, 1994.

FREIRE, Paulo. Pedagogia do oprimido. Rio de Janeiro: Paz e Terra, 2005.

FREIRE, Paulo. Pedagogia da Autonomia: saberes necessários à prática educativa. Rio de Janeiro: Paz e Terra, 1996.

GARCIA, Nilson Marcos Dias. Ensinando a ensinar física: um projeto desenvolvido no Brasil nos anos 1970. In: IV CONGRESSO BRASILEIRO DE HISTÓRIA DA EDUCAÇÃO. Goiânia (s.n.), 2006.

GATTI, Bernadete Angelina; BARRETTO, Elba Siqueira de Sá; ANDRÉ, Marli Elisa Dalmazo De Afonso. Políticas docentes no Brasil: um estado da arte. Brasília, DF: UNESCO, 2011. 300p

GIL, Antônio Carlos. Métodos e Técnicas de Pesquisa Social. 6 ed. São Paulo: Atlas 2010.

KRASILCHIK, Myrian. O Professor e o Currículo das Ciências. São Paulo: EPU: EDUSP, 1987.

LELLIS, Mirian; MUELLER, Eduardo Ribeiro. O PARFOR da UFMT: um olhar sobre a gestão de cursos. In: SOUZA, M. I. P.O.; FRISSELLI, R. R. Z. (Orgs). O PARFOR, a formação e a ação dos professores da educação básica, v. 2. Londrina: PARFOR/UEL, 2017.

LÜDKE, Menga; ANDRÉ, Marli Elisa Dalmazo De Afonso. Pesquisa em educação: abordagens qualitativas. São Paulo, SP: Editora Pedagógica e Universitária, 1986.

MARCONI, Marina De Andrade; LAKATOS, Eva Maria. Metodologia do trabalho científico: procedimentos básicos, pesquisa bibliografia, projeto e relatório, publicações e trabalhos científicos. 6.ed. São Paulo: Atlas, 2006. 
MATTHEWS, Michael. S. História, filosofia e ensino de ciências: a tendência atual de reaproximação. Caderno Brasileiro de Ensino de Física, v. 12, n. 3, p. 164-214, 1995.

MORIM, Edgar. Ciência com Consciência. 7. ed. Rio de Janeiro: Bertrand Brasil, 2003.

NOVOA, Antonio. Vidas de Professores. 2. ed. Porto: Porto Editora, 2007.

OLIVEIRA, Renato José De. A escola e o ensino de ciências. São Leopoldo: Editora Unisinos, 2000.

RAMOS, Fernanda Peres; NEVES, Marcos Cesar Danhoni.; CORAZZA, Maria Júlia. A ciência moderna e as concepções contemporâneas em discursos de professores-pesquisadores: entre rupturas e a continuidade. Revista Electrónica de Enseñanza de las Ciencias, v. 10, n. 1, p. 84-108, 2011.

TRIVIÑOS, Augusto Nibaldo Silva. Introdução à pesquisa em ciências sociais: a pesquisa qualitativa em educação. São Paulo: Atlas, 1990.

VIDAL, Diana Gonçalves. A fonte oral e a pesquisa em História da Educação: algumas considerações. Educação em Revista, Belo Horizonte, nº 27, jul/1998. 